\title{
Characterization and removal of extra lattice species in faujasites
}

\author{
Michael Stockenhuber ${ }^{a}$, J.A. Lercher ${ }^{\text {b.* }}$ \\ a Institute for Physical Chemistry, Technical University of Vienna, Christian Doppler Laboratory for Heterogenous \\ Catalysis, Getreidemarkt 9, A-1060 Vienna, Austria \\ ${ }^{\mathrm{b}}$ Department of Chemical Technology, University of Twente, Christian Doppler Laboratory for Heterogenous Catalysis, \\ P.O. Box 217, 7500 AE Enschede, Netherlands
}

Received 13 December 1993; accepted 28 June 1994

\begin{abstract}
The acidic properties of dealuminated Y-type zeolites were characterized by infrared (IR) spectroscopy, microcalorimetry, ${ }^{29} \mathrm{Si}$ magic-angle spinning nuclear magnetic resonance (MAS NMR) spectroscopy and temperatureprogrammed desorption (TPD). Microcalorimetric measurements exhibited a uniform heat of adsorption ( $140 \mathrm{~kJ} / \mathrm{mol}$ ) of ammonia on the strong Brönsted acid sites. The differences in the acid site concentrations measured by adsorption of ammonia from the gas phase and by decomposition of ammonium-exchanged zeolites are discussed. The results indicate that parts of the extra lattice material consisting of cationic aluminium oxide species or silica alumina species are removed by ion exchange with aqueous solutions of ammonium hydroxide. Based on this, a method for the controlled removal of extra lattice material was developed.
\end{abstract}

Keywords: Faujasites; Characterization; Microcalorimetry; Infrared spectroscopy; Extra lattice species

\section{Introduction}

At present, dealuminated Y-type zeolites are extensively used as catalytically active components of cracking catalysts. The catalytic behavior of the catalyst is strongly influenced by the concentration, strength and type of the acid sites [1] as well as by the amount of extra framework aluminium (EFAL) species [2]. Thus, the characterization of the strength and concentration of the active sites of these zeolites is of considerable industrial interest.

Generally, the adsorption and desorption of bases are the most widely accepted methods for the evaluation of the acid site concentration of these materials [3-5]. However, a significant

* Corresponding author. difference between the concentration of acid sites determined by the adsorption of ammonia from aqueous solutions and from the gas phase was reported in previous studies [6,7]. In order to account for these differences, the two methods were systematically compared on a series of dealuminated faujasite-type zeolites.

Our preliminary studies suggested that the EFAL species formed by dealumination were the major cause for the observed differences. These species were partly removed from the lattice by treatment of the zeolites with $\mathrm{NH}_{4} \mathrm{OH}$ solutions. In contrast, adsorption of the $\mathrm{NH}_{3}$ from the gas phase did not change the concentration of the extra lattice alumina. This is of particular importance, as these extra lattice species seem to influence the catalytic behaviour of zeolites $[8,9]$. Acid leaching $[10]$ for removal of the extra framework 
species partly destroys the lattice and reduces the concentration of Brönsted acid sites by removing part of the tetrahedrally coordinated $\mathrm{Al}$ [10]. This was not observed after treatment of the dealuminated $\mathrm{Y}$ samples with an aqueous $\mathrm{NH}_{4} \mathrm{OH}$ solution to remove the extra lattice species.

The present paper focuses, thus, on the characterization of the acid sites prior and subsequent to $\mathrm{NH}_{4} \mathrm{OH}$ leaching. The main experimental means employed are thermogravimetry-differential scanning calorimetry (TG-DSC), IR and ${ }^{29} \mathrm{Si}$ MAS NMR spectroscopy.

\section{Experimental}

The adsorption, desorption and surface chemistry of ammonia on several FAU samples, dealuminated by $\mathrm{SiCl}_{4}$, were investigated by TG, DSC, TPD, in situ IR and ${ }^{29}$ Si MAS NMR spectroscopy. In order to probe the surface chemistry in aqueous solutions of ammonia, the samples were treated in aqueous $\mathrm{NH}_{4} \mathrm{OH}$ solutions of concentrations varying from 0.01 to $24 \mathrm{~mol} / \mathrm{l}$ at $300 \mathrm{~K}$. The overall $\mathrm{Al}$ concentration of the samples was determined by energy dispersive $\mathrm{X}$-ray absorption spectroscopy (EDAX).

\subsection{Infrared spectroscopic measurements}

For the IR spectroscopic measurements the samples were pressed into self-supporting wafers with a compact pressure of approximately $10^{8} \mathrm{~N} / \mathrm{cm}^{2}$. The wafers were placed in a sample holder in the center of a furnace and heated in situ to temperatures between 750 and $820 \mathrm{~K}$ with increments of $10 \mathrm{~K} / \mathrm{min}$. The IR spectra were recorded on a Bruker IFS 88 spectrometer using a spectral resolution of $4 \mathrm{~cm}^{-1}$. A detailed description of the system is given elsewhere [11].

\subsection{Calorimetric measurements}

A modified Setaram TG-DSC 111 instrument was used for measuring the heat of ammonia adsorption. The sample was pressed into thin wafers (in the same way as for IR spectroscopic measurements) and placed in a small quartz cruci- ble suspended on quartz glass suspension wires. The crucibles were hanging without physical contact with the quartz tubes in the most sensitive region of the calorimeter. The calibration of the calorimeter was performed over the whole temperature range $(380-1060 \mathrm{~K})$ by phase transitions of different inorganic samples. The calorimeter was connected to a vacuum system with a base pressure of $<10^{-4} \mathrm{~Pa}$ equipped with a Balzers QMG420 mass spectrometer. Typically, $10 \mathrm{mg}$ of the sample were heated to $800 \mathrm{~K}$ with increments of $10 \mathrm{~K} / \mathrm{min}$. During the activation, the change in the gas phase and the calorimetric and the gravimetric signals were recorded simultaneously. The sample was cooled to $475 \mathrm{~K}$ at which the adsorption was carried out by introducing small amounts of ammonia into the calorimeter.

\section{Results}

The acid site concentration of the parent dealuminated FAU (HY-5) and the sample treated with $1 \mathrm{~N} \mathrm{NH}_{4} \mathrm{OH}$ solution (HY-5-1.0) was compared by means of TPD of ammonia. The TPD curves normalized to the mass of the catalyst are plotted in Fig. 1. The integrated area of the desorption peak at $600 \mathrm{~K}$, which is attributed to the desorption of ammonia from strong Brönsted acid sites [12,13], is significantly larger for the samples treated with aqueous ammonia solutions than for the same sample after adsorption of ammonia from the gas phase.

Fig. 2 shows the normalized IR spectra of the sample treated with an aqueous $1 \mathrm{~N} \mathrm{NH}_{4} \mathrm{OH}$ solution for $23 \mathrm{~h}$ at room temperature and of the same sample in contact with $10^{-1} \mathrm{~Pa} \mathrm{NH}$ from the gas phase. In both cases a strong absorption band at $3615 \mathrm{~cm}^{-1}$, attributed to $\mathrm{OH}$ stretching vibration bands of extra framework species [14,15], was observed. In addition, bands at 1975 and $1865 \mathrm{~cm}^{-1}$ (which are assigned to the overtones of the zeolite lattice deformation vibrations [16], bands between 3500 and $2500 \mathrm{~cm}^{-1}$ (attributed to $\mathrm{N}-\mathrm{H}$ stretching vibrations) and a band at $1460 \mathrm{~cm}^{-1}\left(\mathrm{NH}_{4}^{+}\right.$deformation vibrations) were detected. The IR spectra indicate a higher concentration of $\mathrm{NH}_{4}^{+}$in the $\mathrm{NH}_{4} \mathrm{OH}$ ion-exchanged 
Rate of desorption [arb. units]

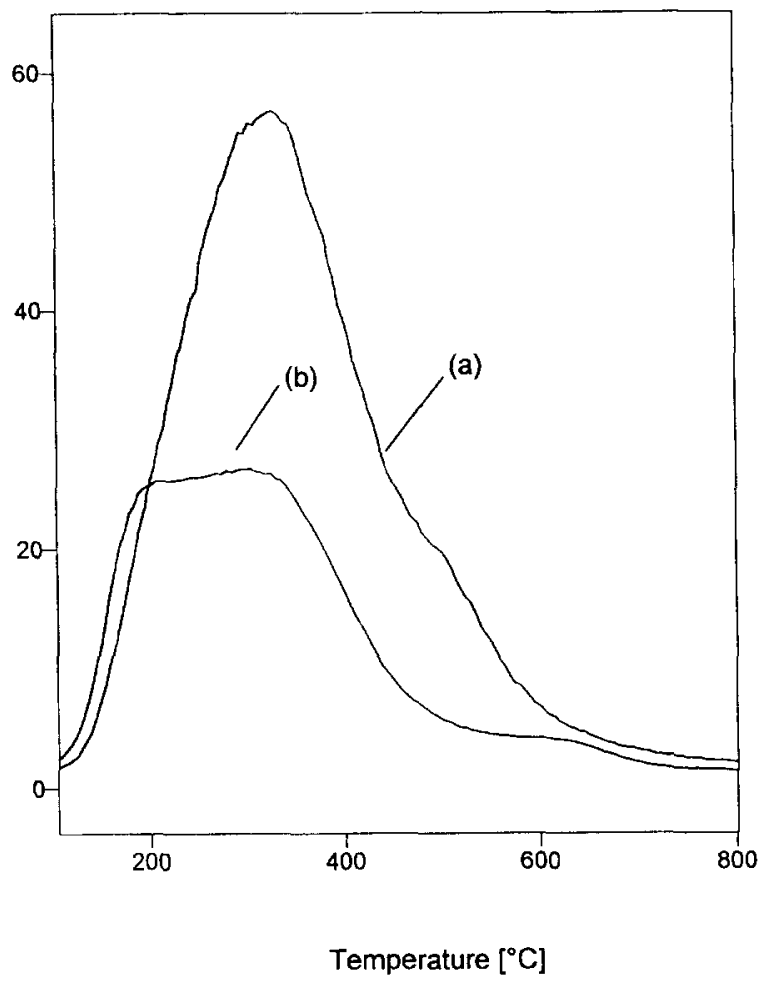

Fig. 1. Comparison of the temperature-programmed desorption from HY-5 (b) after adsorption of $10^{-1} \mathrm{~Pa} \mathrm{NH} \mathrm{NH}_{3}$ and (a) after ion exchange with $1 \mathrm{~N} \mathrm{NH}_{4} \mathrm{OH}$ solution.

zeolites than in zeolites with $\mathrm{NH}_{3}$ adsorbed from the gas phase. This is in perfect agreement with the TPD results.

In order to probe whether the variations in the concentration of ammonium ions are caused by the mode of introduction of the ions or are due to a modification of the zeolite and its acid sites, the parent dealuminated Y-type zeolites were treated with aqueous ammonia solutions of concentrations varying from 0.01 to $24 \mathrm{~mol} / 1$. HY-5-0.01, HY-5$0.1 \mathrm{~A}$ and $\mathrm{HY}-5-1.0$ correspond to materials treated with $0.01,0.1$ and $1.0 \mathrm{~mol} / 1 \mathrm{NH}_{4} \mathrm{OH}$, respectively. The physicochemical characteristics of these materials together with those of the parent material and HZSM5 are compiled in Table 1.

The overall aluminium concentration was determined by EDAX spectroscopy, the lattice $\mathrm{Al}$ concentration was assessed by ${ }^{29} \mathrm{Si}$ MAS NMR and for some samples by the unit cell dimensions
Absorbance

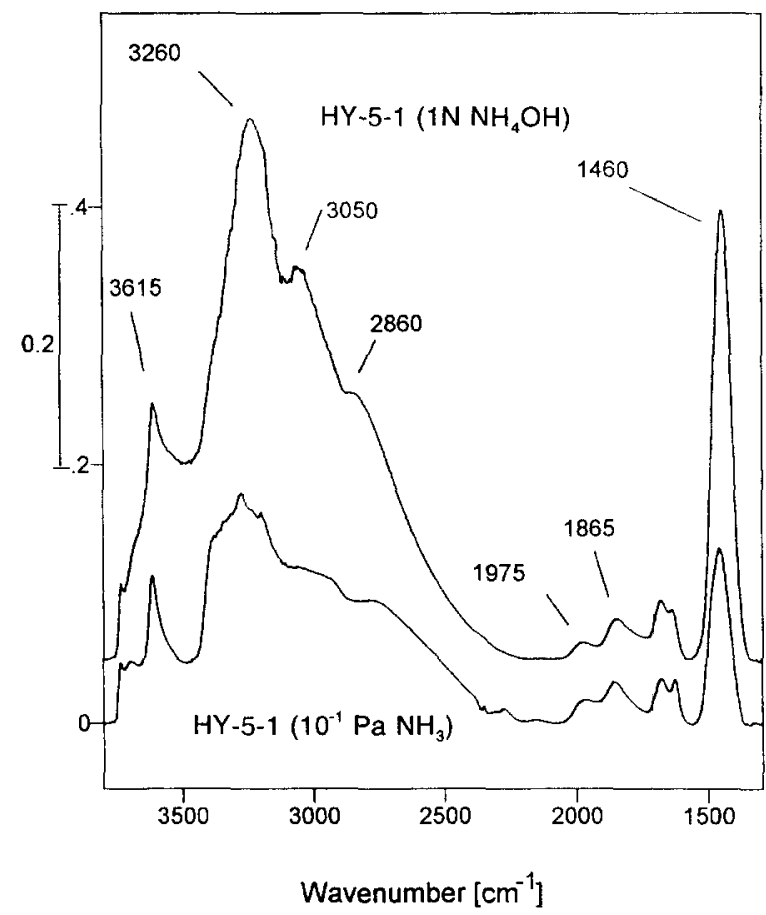

Fig. 2. IR spectra of $\mathrm{HY}-5$ in contact with $10^{1} \mathrm{~Pa} \mathrm{NH_{3 }}$ and HY-5 after ion exchange with $1 \mathrm{~N} \mathrm{NH}_{4} \mathrm{OH}$ solution.

derived from X-ray diffraction (XRD) measurements [17]. The concentration of strong Brönsted acid sites was measured by acid site titration with ammonia followed by TG-DSC. The Brönsted acid site concentrations given in Table 1 equal the concentrations of adsorbed ammonia liberating a heat of adsorption higher than $120 \mathrm{~kJ} / \mathrm{mol}$. In Fig. 3, the evolved heat of adsorption is plotted versus the concentration of ammonia adsorbed. The maximum concentration of ammonia that is strongly adsorbed is indicated by lines $\mathrm{A}$ and $\mathrm{B}$. The position of these lines was chosen at the concentration where the heat of adsorption starts to decrease.

The effect of the treatment with aqueous ammonia solutions on the intensity of the bands due to $\mathrm{OH}$ stretching vibrations are compared in Fig. 4. In agreement with the literature, the IR spectra of dealuminated zeolite $Y$ shows at least five different $\mathrm{OH}$ bands $[15,18,19]$. The main bands of the activated samples are observed at $3630 \mathrm{~cm}^{-1}$, 
Table 1

Concentrations of aluminium and acid sites and relative fractions of different extra lattice phases

\begin{tabular}{|c|c|c|c|c|c|c|}
\hline \multirow[t]{3}{*}{ Zeolite } & \multicolumn{4}{|c|}{ Concentration $(\mathrm{mol} / \mathrm{g})$} & \multirow{3}{*}{$\begin{array}{l}\text { Relative fraction } \\
\text { of EFAL-OH }\end{array}$} & \multirow{3}{*}{$\begin{array}{l}\text { Relative fraction of } \\
\text { silica in amorphous } \\
\text { aluminosilicate }^{d}\end{array}$} \\
\hline & \multicolumn{2}{|c|}{ Aluminium } & \multicolumn{2}{|l|}{ Acid sites } & & \\
\hline & $\begin{array}{l}\text { Total } \\
(\text { EDAX) }\end{array}$ & $\begin{array}{l}\text { Tetrahedrally } \\
\left({ }^{29} \mathrm{Si} \text { NMR }\right)\end{array}$ & $\begin{array}{l}\mathrm{NH}_{3} \\
\text { desorption }^{\mathrm{a}}\end{array}$ & $\begin{array}{l}\mathrm{NH}_{3} \\
\text { adsorption }\end{array}$ & & \\
\hline$\overline{\mathrm{HY}-5}$ & $2.7 \cdot 10^{-3}$ & $2.1 \cdot 10^{-3}$ & - & $6.6 \cdot 10^{-4}$ & 1.04 & $5.5 \cdot 10^{-2}$ \\
\hline HY $-5-0.01$ & $3.6 \cdot 10^{-3}$ & $1.8 \cdot 10^{-3}$ & $1.9 \cdot 10^{-3}$ & $8.6 \cdot 10^{-4}$ & 0.85 & $1.1 \cdot 10^{-1}$ \\
\hline HY-S-0.1A & $3.7 \cdot 10^{-3}$ & $2.1 \cdot 10^{-3}$ & $2.1 \cdot 10^{-3}$ & $1.2 \cdot 10^{-3}$ & 0.49 & $6.7 \cdot 10^{-2}$ \\
\hline HY-5-0.1B & $3.6 \cdot 10^{-3}$ & $1.7 \cdot 10^{-3}$ & $1.6 \cdot 10^{-3}$ & $7.4 \cdot 10^{-4}$ & 0.90 & $9.4 \cdot 10^{-2}$ \\
\hline HY-5-0.1C & $3.7 \cdot 10^{-3}$ & $2.2 \cdot 10^{-3}$ & $2.1 \cdot 10^{-3}$ & $8.9 \cdot 10^{-4}$ & 0.67 & $7.2 \cdot 10^{-2}$ \\
\hline HY $-5-1.0$ & $3.4 \cdot 10^{-3}$ & $2.1 \cdot 10^{-3}$ & $2.1 \cdot 10^{-3}$ & $8.2 \cdot 10^{-4}$ & 0.68 & $6.8 \cdot 10^{-2}$ \\
\hline HZSM5 & $4.4 \cdot 10^{-4}$ & $4.1 \cdot 10^{-4}$ & $4.1 \cdot 10^{-4}$ & $4.1 \cdot 10^{-4}$ & - & - \\
\hline
\end{tabular}

${ }^{\text {a }}$ Concentration of ammonia desorbed during heating the $\mathrm{NH}_{4}^{+}$-exchanged samples.

${ }^{b}$ Concentration of ammonia strongly adsorbed at $475 \mathrm{~K}$ determined by TG-DSC measurements.

${ }^{\circ}$ Fraction of the intensity of the IR band at $3615 \mathrm{~cm}^{-1}$ and the intensities of the Brönsted OH stretching bands: $I_{\mathrm{v}_{3615}} / \sum I_{\text {SiOHAl groups }}$

${ }^{\mathrm{d}}$ Fraction of the ${ }^{29} \mathrm{Si}$ MAS NMR band at $112 \mathrm{ppm}$ and the sum of all Si bands: $I_{\delta_{112}} / \sum I_{\mathrm{Si}}$.

Heat of adsorption [kJ/mol]

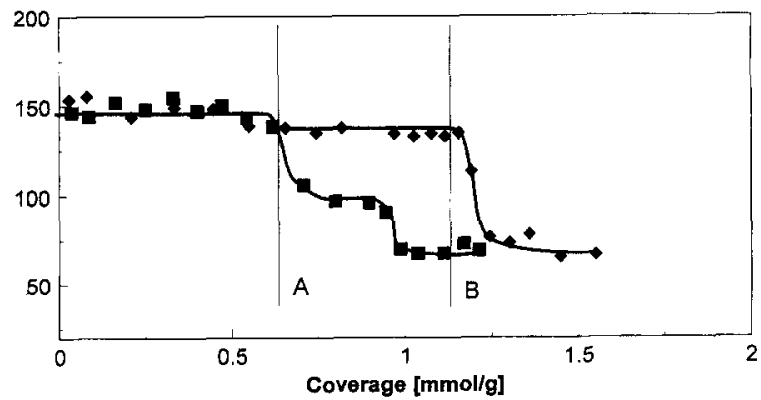

Fig. 3. Heat of adsorption versus amount of ammonia adsorbed for samples HY-5 (ם) and HY-5-0.1-A ( $\bullet$ ).

attributed to SiOHAl groups in the supercages [high-frequency (HF) band], $3560 \mathrm{~cm}^{-1}$, attributed to SiOHAl groups in the sodalite cages [lowfrequency (LF) band], and $3602 \mathrm{~cm}^{-1}$, attributed to $\mathrm{OH}$ groups disturbed by extra framework species [20-22]. Comparison with Fig. 2 shows that the band at $3602 \mathrm{~cm}^{-1}$ is superimposed by a strong band at $3615 \mathrm{~cm}^{-1}$. The intensities of the $\mathrm{HF}$ and LF bands increase by the treatment with $0.1 \mathrm{~N} \mathrm{NH}_{4} \mathrm{OH}$ solution and the intensity of the band at $3602 \mathrm{~cm}^{-1}\left(3615 \mathrm{~cm}^{-1}\right)$ decreases (Fig. 4). This suggests that the concentration of extra framework material is reduced and the concentration of the Brönsted acid sites is increased.

This conclusion is supported by comparison of

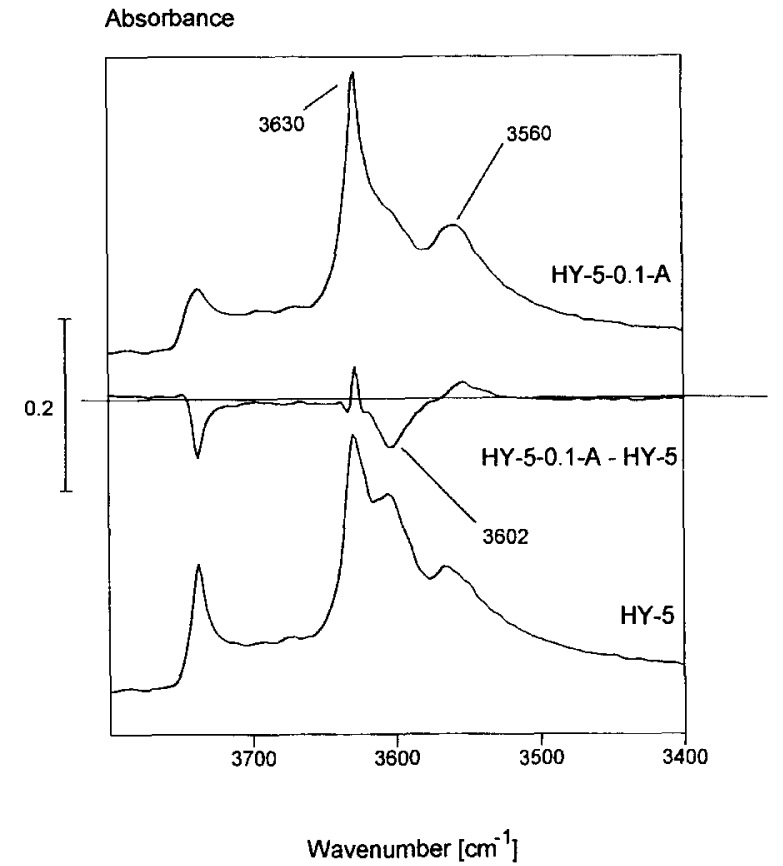

Fig. 4. IR spectra of the activated sample HY-5 and HY-5$0.1-\mathrm{A}$ in the $\mathrm{OH}$ stretching vibration region.

the IR spectra of samples HY-5 and HY-5-0.1-A before and after adsorption of $10^{-1} \mathrm{~Pa}$ ammonia at $300 \mathrm{~K}$ (Fig. 5). The increase in the intensity of the band at $1460 \mathrm{~cm}^{-1}$ indicates that the concentration of ammonia bound to Brönsted acid 


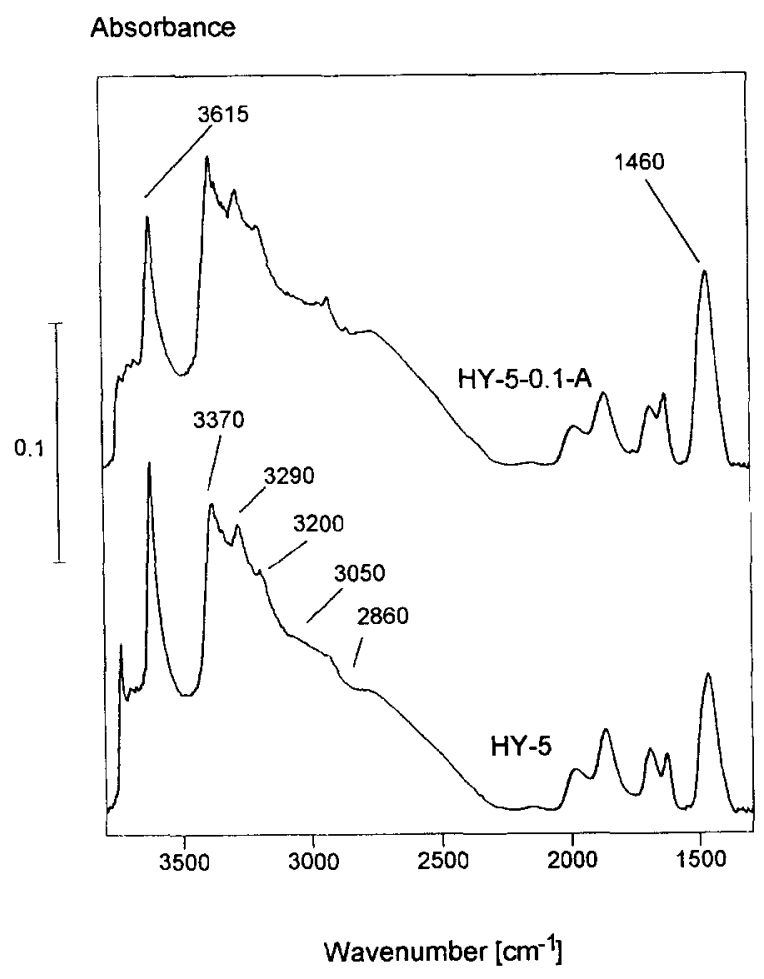

Fig. 5. IR spectra of sample HY-5 and HY-5-0.1-A after adsorption of $10^{-1} \mathrm{~Pa} \mathrm{NH}_{3}$.

sites is larger for HY-5-0.1-A than for HY-5. Additionally, the band at $3615 \mathrm{~cm}^{-1}$, which is attributed to non-acidic $\mathrm{OH}$ groups related to extra framework species [20-22], is substantially reduced after $\mathrm{NH}_{4} \mathrm{OH}$ treatment.

Two explanations for these observations are conceivable. (i) The treatment with $\mathrm{NH}_{4} \mathrm{OH}$ causes a reinsertion of aluminium from the extra framework phases into the zeolite framework. (ii) The extra framework phases act partially as counter cations for the $\mathrm{SiO}^{-} \mathrm{Al}$ groups which are replaced by $\mathrm{NH}_{4}^{+}$ions and subsequently washed out by the treatment with a basic solution.

To differentiate between these two models, the Al concentrations derived from ${ }^{29} \mathrm{Si}$ MAS NMR spectra of the different samples are compared in Table 1. The data indicate that the concentration of $\mathrm{Al}$ in the lattice after the modification procedure with aqueous ammonia solutions is nearly identical with that of the parent material supporting the second model.

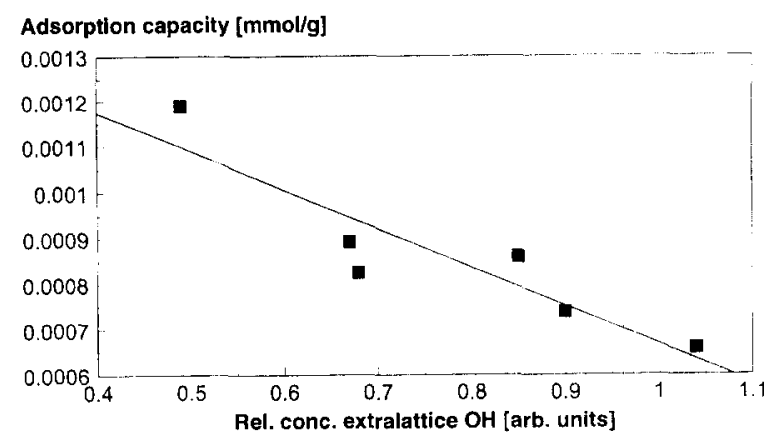

Fig. 6. Relationship between the adsorption vapacity for ammonia and the relative intensity of the remaining IR band at $3615 \mathrm{~cm}^{-1}$ after adsorption of $10^{-1} \mathrm{~Pa} \mathrm{NH}_{3}$ (normalized to the sum of the intensities of the bridged $\mathrm{OH}$ groups).

For a more quantitative description of the extra lattice material present in the different zeolites, the relative fractions of the different extra lattice phases derived by the two methods are also compared in Table 1. The fraction of cationic EFAL species was calculated by the relative intensity of the IR band at $3615 \mathrm{~cm}^{-1}$ after adsorption of $10^{-1} \mathrm{~Pa}$ ammonia, and the concentration of the aluminosilicate was calculated by the relative intensity of the ${ }^{29} \mathrm{Si}$ MAS NMR peak at $112 \mathrm{ppm}$, attributed to amorphous aluminosilicates [23]. The numbers given are based on the ratio of the integrals of the remaining band at $3615 \mathrm{~cm}^{-1}$ after ammonia adsorption to the integrals of the bridged $\mathrm{OH}$ groups as well as on the ratio between the integrals of the aluminosilicate signal and the sum of the ${ }^{29} \mathrm{Si}$ MAS NMR signals. The samples HY5-0.1-A. HY-5-0.1-B and HY-5-0.1-C were slurried for 138,19 and $118 \mathrm{~h}$ in $0.1 \mathrm{~N} \mathrm{NH}_{4} \mathrm{OH}$ at $300 \mathrm{~K}$. respectively.

Fig. 6 illustrates the linear decrease of the adsorption capacity for strongly adsorbed ammonia with increasing relative intensity of the band at $3615 \mathrm{~cm}^{-1}$.

\section{Discussion}

\subsection{Characterization of the acid sites}

Assuming a stoichiometry of one molecule of ammonia adsorbed per SiOHAl group, the ${ }^{29} \mathrm{Si}$ 
MAS NMR data and the amount of ammonia desorbed from the samples during activation (see Table 1) suggest that all strong Brönsted acid sites are accessible for ammonium ions in aqueous solution. In contrast, after adsorption of $\mathrm{NH}_{3}$ from the gas phase (after the first activation) a significant lower amount of ammonia desorbed from the zeolite (see Fig. 1). It reached only one third to one half of the concentration of $\mathrm{NH}_{3}$ of the samples after ion exchange in aqueous solution measured with TPD. Previously, this was explained by partial dehydroxylation of the samples during the temperature treatment [6] accompanied by partial removal of aluminium from the zeolite lattice. The ${ }^{29}$ Si MAS NMR measurements, however, clearly indicate that this is not the case in the present study.

As both approaches led to nearly identical values of $\mathrm{NH}_{4}^{+}$concentration in the case of HZSM5 (see Table 1), we are able to rule out the possibility of an inherent difference in the values measured by aqueous ion exchange and by ammonia adsorption from the gas phase. Thus, ion exchange caused at least partially the replacement of aluminium oxide or hydroxide species, which assumed the role of charge-compensating metal cations. Because the concentration of tetrahedrally coordinated aluminium (as estimated from ${ }^{29} \mathrm{Si}$ MAS NMR) perfectly agrees with the concentration of $\mathrm{NH}_{4}^{+}$ions after ion exchange, we conclude that by the treatment with $1 \mathrm{~N} \mathrm{NH}_{4} \mathrm{OH}$ all cationic alumina species were replaced by $\mathrm{NH}_{4}^{+}$. After aqueous exchange and thermal treatment, some of the EFAL species still present in the zeolite are able to block again some of the acid sites. Thus, if the EFAL species are not completely removed, a decreased adsorption capacity for ammonia from the gas phase is found.

The acid sites that were able to adsorb $\mathrm{NH}_{3}$ from the gas phase were quite uniform in strength. The heat of ammonia adsorption at $473 \mathrm{~K}$ was $140 \pm 10 \mathrm{~kJ} / \mathrm{mol}$ as long as one $\mathrm{NH}_{3}$ molecule was adsorbed per acid site. This value agrees perfectly well with previous reported values [24-27].

The IR spectra (see Fig. 7) clearly indicate that adsorption did not take place on $\mathrm{SiOH}$ (band at $3737 \mathrm{~cm}^{-1}$ ) and on $\mathrm{AlOH}$ groups of the extra lattice material (band at $3615 \mathrm{~cm}^{-1}$ ). The $\mathrm{NH}$ deformation vibrations indicate that most of the ammonia molecules were adsorbed as $\mathrm{NH}_{4}^{+}$ions.

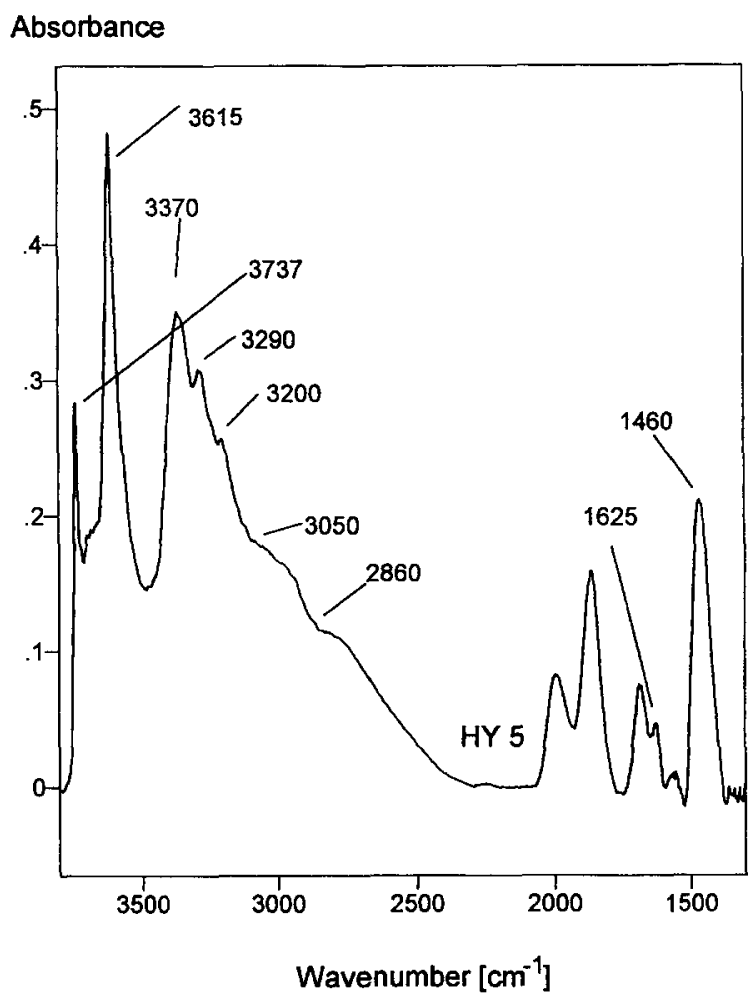

Fig. 7. IR spectrum of $10^{-1} \mathrm{~Pa}$ ammonia in contact with $\mathrm{HY}-5$ at $473 \mathrm{~K}$.

Only a small fraction was adsorbed on accessible Lewis acid sites $(13 \%$ of the integrated areas of the bands at 1625 and $1460 \mathrm{~cm}^{-1}$ ).

Thus, we conclude that (for characterization purposes) the aqueous ion exchange will provide the total concentration of tetrahedrally coordinated $\mathrm{Al}$ in the lattice. Adsorption of ammonia from the gas phase, on the other hand, will provide the concentration of the strong Brönsted acid sites in the zeolite which are accessible for reactant molecules.

In the following we will outline the possibilities to use the $\mathrm{NH}_{4} \mathrm{OH}$ treatment for controlled removal of the extra lattice alumina from the channels of the samples studied.

\subsection{Removal of the extra framework aluminium species}

The increase in the concentration of ammonia adsorbed from the gas phase and the decrease in 
the intensity of the IR band at $3615 \mathrm{~cm}^{-1}$ after treatment of the zeolite with $\mathrm{NH}_{4} \mathrm{OH}$ solution (see Fig. 6) suggest that EFAL oxides are removed during the modification procedure. Because adsorption of ammonia from the gas phase occurs quantitatively on all strong Brönsted acid sites for the samples studied (concluded from the complete disappearance of the HF and LF IR band after adsorption of ammonia), we rule out that EFAL reduces the concentration of acid sites in the parent material by physical blocking. Thus, we propose that most of the EFAL in the parent material is present as cationic aluminum oxide species, which is then partially removed during the $\mathrm{NH}_{4} \mathrm{OH}$ treatment. The inverse linear dependence between the chemisorption capacity for ammonia and the concentration of EFAL further indicates that the cationic extra framework species in the zeolite channels is uniform in size and nature.

Although we have clear evidence that EFAL is removed from the zeolite pores, the overall aluminum concentration increased by some $30 \%$ during the treatment (see Table 1). Because the concentration of the tetrahedrally coordinated aluminum in the lattice remained constant throughout all modification procedures reported here, we conclude that neither aluminum insertion into $[28,29]$ nor aluminum removal from [10] the lattice occurs. The increase in the overall aluminum concentration thus indicates that $\mathrm{SiO}_{2}$ (present in the extra lattice material of the parent zeolite) was also removed during the ion-exchange procedure. This conclusion is supported by the decrease of the $\mathrm{SiOH}$ band at $3737 \mathrm{~cm}^{-1}$ (suggesting a decrease of the concentration of the SiOH groups) after ion exchange. The $\mathrm{SiCl}_{4}$ treatment that was used to produce the parent material is speculated to be the source for this silica material outside the zeolite crystals, because the relative intensity of the band at $3737 \mathrm{~cm}^{-1}$ in the parent zeolite is remarkably high compared with steam-dealuminated or as-synthesized faujasites [14]. The remaining silica outside the zeolite crystals seems to react in part with aluminum that is removed by the ionexchange procedure. This is concluded from the increasing ${ }^{29} \mathrm{Si}$ MAS NMR peak at $112 \mathrm{ppm}$, which is characteristic for amorphous aluminosilicate [23]. The pure silica does not seem to contribute to that signal. A semiquantitative estimate of the relative amount of aluminum in the two extra lattice phases is given in Fig. 8.

It should be especially noted that the aluminum concentration in the lattice remained unaffected throughout all treatments with diluted $\mathrm{NH}_{4} \mathrm{OH}$ solutions. The use of concentrated $\mathrm{NH}_{4} \mathrm{OH}$ solutions, however, led to the partial destruction of the zeolite (the decrease in the reflection intensities and scattering from amorphous material was detected by XRD). This suggests an approximately equal stability of the $\mathrm{Si}-\mathrm{O}-\mathrm{Si}$ and $\mathrm{Si}-\mathrm{O}-\mathrm{Al}$ bonds with respect to hydrolysis in a basic environment.
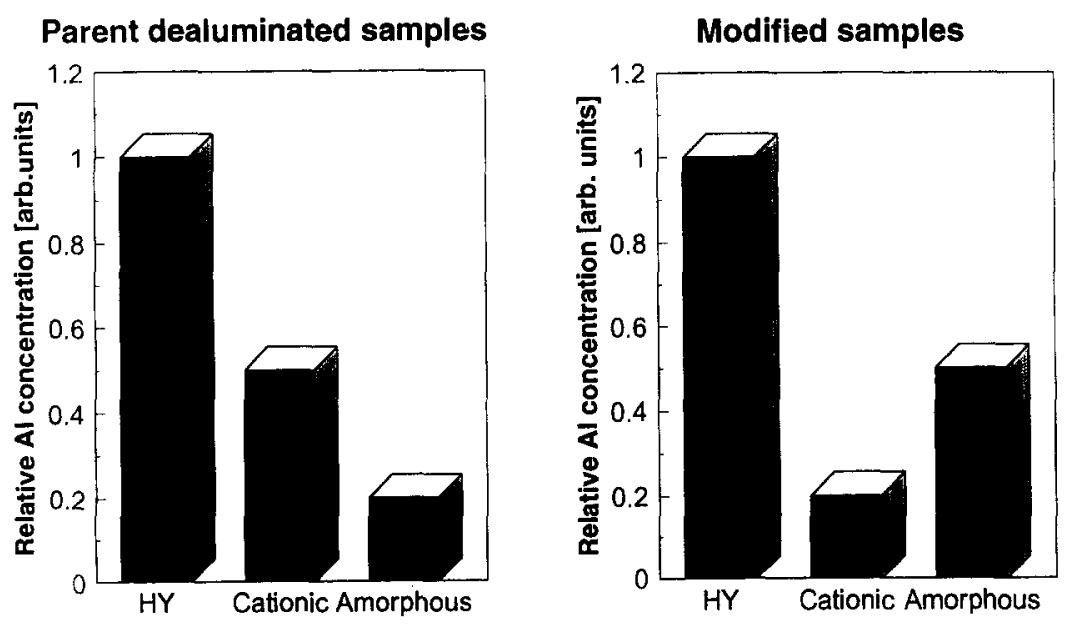

Fig. 8. Schematic presentation of the Al concentration in the phases of the dealuminated zeolites 
The uniform and identical strength of the acid sites in the presently investigated samples contradicts the attribution of high acid strength to $\mathrm{OH}$ groups perturbed by EFAL IR band at $3602 \mathrm{~cm}^{-1}$ ) as proposed by Lunsford et al. [20]. Not even a small fraction of the acid sites of the presently investigated dealuminated samples showed an enhancement in acid strength. The strength of all acid sites, however, decreased slightly $(\Delta q=$ $10 \mathrm{~kJ} / \mathrm{mol}$ ) after removal of the EFAL from the zeolite pores. Thus, we conclude that weak longrange interactions between EFAL and the zeolite lattice exist.

\section{Conclusions}

The main difference between the adsorption capacity of dealuminated FAU for ammonia adsorbed from aqueous solutions and from the gas phase is concluded to be due to the leaching of EFAL species from the zeolite pores in aqueous ammonia solutions. This procedure enhances the adsorption capacity up to $100 \%$. The extent of adsorption capacity enhancement depends subtly on the concentration of the $\mathrm{NH}_{4} \mathrm{OH}$ solutions, the time of treatment and the washing procedures. It is concluded that two extra framework species exist: (i) one that is rich in alumina, has cationic character and balances the charge of tetrahedrally coordinated aluminium in the zeolite lattice; (ii) one that is rich in silica and is located mainly outside the zeolite channels. The strength of the acid sites is not changed during the modification procedure. There is a slight decrease in the overall heat of adsorption of the modified compared with the parent samples, which implies a long-range interaction between the extra lattice phases and the $\mathrm{OH}$ groups of the zeolites. The aluminium concentration in the lattice is not significantly altered by that procedure. With respect to the characterization of zeolites, our results show that ammonia TPD after aqueous ion exchange indicates the concentration of tetrahedrally coordinated aluminium framework atoms (i.e. the maximum concentration of strong Brönsted acid sites available). Adsorption of ammonia from the gas phase, on the other hand will yield the concen- tration of the Brönsted acid sites accessible to a gaseous reactant.

\section{Acknowledgements}

We gratefully thank Mr. Neil Hayes, Prof. Richard Joyner and the SERC Solid State NMR Facility at UMIST for the measurement of the ${ }^{29}$ Si MAS NMR spectra, Dr. H. Wernisch for the measurements of the EDAX spectra and the Christian Doppler Laboratory for financial support.

\section{References}

[1] A.L. Klyachko, G.I. Kapustin, T.R. Brueva and A.M. Rubinstein, Zeolites, 7 (1987) 119.

[2] R.M. Lago, W.O. Haag, R.J. Mikovski, D.H. Olson, S.D. Bellring, K.D. Schmitt and G.T. Kerr, New Dev. Zeolite Sci. Technol., 28 (1986) 677.

[3] N. Topsoe, K. Pedersen and E.G. Derouane, J. Catal, 70 (1981) 41

[4] E. Dima and L.V.C. Rees, Zeolites, 10 (1990) 8.

[5] D. Chen, S. Sharma, N. Cardona Martinez, J.A. Dumesic, V.A. Bell, G.D. Hodge and R.J. Madon, J. Catal, 136 (1992) 392.

[6] A. Auroux, Y.S. Jin, L. Benoist and J.C. Vedrine, Appl. Catal, 36 (1988) 323

[7] H. Stach, J. Jänchen, H. Jerschkewitz, U. Lohse, B. Parlitz, B. Zibrowius and M. Hunger, J. Phys. Chem., 96 (1992) 8473.

[8] R.A. Beyerlein, G.B. McVicker, L.N. Yacullo and J.J. Ziemiak, ACS Meeting, Div. Petrol. Chem., N.Y., 31 (1986) 190.

[9] R.A. Beyerlein, G.B. McVicker, L.N. Yacullo and J.J. Ziemiak, J. Phys. Chem., 92 (1986) 1967.

[10] U. Lohse, E. Löffler, M. Hunger, J. Stöckner and V. Patzelova, Zeolites, 7 (1987) 11.

[11] C. Halik, J.A. Lercher and H. Mayer, J. Chem. Soc., Faraday I, 84 (1988) 4457.

[12] C.V. Hidalgo, H. Itoh, T. Hattori, M. Niwa and Y. Murakami, J. Catal., 85 (1984) 362

[13] B.M. Lok, B.K. Marcus and C.L. Angell, Zeolites, 6 (1986) 185.

[14] L. Kubelkova, V. Seidl, J. Novakova, S. Bednarova and P. Jiru, J. Chem. Soc., Faraday I, 80 (1984) 1367.

[15] P.A. Jacobs and J.B. Uytterhoeven, J. Chem. Soc., Faraday 1, 69 (1973) 373.

[16] A. Jentys and J.A. Lercher, Stud. Surf. Sci. Catal, 46 (1989) 585.

[17] D.W. Breck and E.M. Flanigen, Molecular Sieves, Vol. 47, Society of Chemical Industry, London, 1968. 
[18] S. Khabtou, T. Chevreau, J.C. Lavalley, personal communication.

[19] P.O. Fritz and J.H. Lunsford, J. Catal, 118 (1989) 85.

[20] F. Lonyi and J.H. Lunsford, J. Catal., 136 (1992) 566.

[21] M.A. Makarova and J. Dwyer, J. Phys. Chem., 9? (1993) 6337.

[22] A. Chambellan, T. Chevreau, S. Khabtou, M. Marzin and J.C. Lavalley, Zeolites, 12 (1992) 306.

[23] J. Datka, W. Kolidtiejski, J. Klinowski and B. Sulikowski. Catal. Lett., 19 (1993) 159.

[24] D.J. Parillo and R.J. Gorte, J. Phys. Chem., 97 (1993) 8786 .
[25] A. Auroux, V. Bolis, P. Wierzchowski, P.C. Gravelle and J.C. Vedrine, J. Chem. Soc., Faraday I, 75 (1979) 2544

[26] R.D. Shannon, K.H. Gardner, R.H. Staley, G. Bergeret. P. Gallezo1 and A. Auroux. J. Phy's. Chem. 89 (1985) 4778 .

[27] A. Auroux and Y. Ben Taarit, Can. J. Chem. 66 (1988) 1013

[28] J. Klinowski, H. Hamdan, A. Corma. V. Fornes, M. Hunger and D. Freude. Catal. Lett., 3 ( 1989) 263.

[29] W. Reschetilowski, W.D. Einicke, M. Jusek, R. Schöllner, D. Freude, M. Hunger and J. Klinowski, Appl. Catal., 56 (1989) L15. 